\title{
Z5

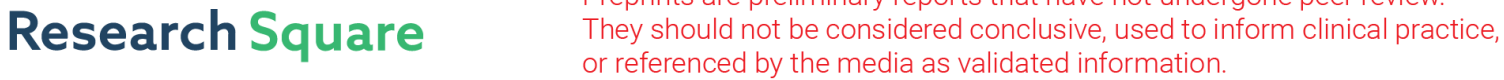

\section{Screening of Graves' Disease Susceptibility Genes by Whole Exome Sequencing in a Three-generation Family}

\section{Zhuoqing Hu}

Department of Endocrinology, The Second Affiliated Hostipal of Guangzhou Medical University

\section{Wei Li}

Huizhou Health Science Polytechnic

\section{Miaosheng Li}

Department of Endocrinology, Affiliated Hospital of Guangdong Medical University, Zhanjiang

\section{Hao Wei}

Department of Endocrinology, Affiliated Hospital of Guangdong Medical Univeristy, Zhanjiang

\section{Zhihui Hu}

Department of Endocrinology, Affiliated Hospital of Guangdong Medical University, Zhanjiang

\section{Yanting Chen}

Department of Endocrinology, Affiliated Hospital of Guangdong Medical University, Zhanjiang

Ai Luo

Department of Endocrinology, The Second Affiliated Hospital of Guangzhou Medical University

Wangen Li ( $\sim$ liwg660@126.com )

Department of Endorcrinology, The Second Affiliated Hospital of Guangzhou Medical University, Guangzhou510220, China https://orcid.org/0000-0002-6138-7320

\section{Research article}

Keywords: Graves' disease, susceptibility genes, three generations, Whole Exome Sequencing

Posted Date: November 20th, 2020

DOI: https://doi.org/10.21203/rs.3.rs-33213/v2

License: (c) (i) This work is licensed under a Creative Commons Attribution 4.0 International License. Read Full License 


\section{Abstract}

Background: Graves' disease(GD) has a tendency for familial aggregation, but it is uncommon to occur in more than two generations. However, little is known about susceptibility genes for GD in the threegeneration family.

Methods: DNA were extracted from three-generation familial GD patient with a strong genetic background in a Chinese Han population. The Whole Exome Sequencing (WES) was utilized to screen the genome for SNVs associated with GD and the Sanger Sequencing was used to confirm the potential disease-causing genes.

Results: In the case study, there were five patients with Graves' disease(GD) from a three-generation family. The SNVs of MAP7D2(c. 452C>T: p. A151V), SLC1A7(c. 1204C>T: p. R402C), TRAF3IP3(c. 209A>T: p. N70I), PTPRB(c. 3472A>G: p. S1158G), PIK3R3(c. 121C>T: p. P41S), DISC1(c. 1591G>C: p. G531R) were found to be associated with the familial GD and the Sanger sequencing had confirmed these variations. Furthermore, PolyPhen-2 score showed that the variants in TRAF3IP3, PTPRB, PIK3R3 are more likely to change protein functions.

Conclusion: The MAP7D2, SLC1A7, TRAF3IP3, PTPRB, PIK3R3, DISC1 may be the candidate susceptibility genes for familial GD from a three generations family.

\section{Background}

Graves' disease is a thyroid-related autoimmune disorder which is caused by a complex interaction between susceptibility genes and multiple environmental factors. Previous familial and twin studies had shown that there was an association of genetic factors with Graves' disease in $79 \%$ cases of Graves' Disease which influenced the familial clustering in GD[1]. People with other autoimmune diseases such as type 1 diabetes or rheumatoid arthritis are also more likely to suffer from this disease. In addition, past reports reported that smoking increases the chance of Graves' Disease. Other causes of Graves' Disease may also include stress, infection, or childbirth. The prevalence of overt hyperthyroidism ranges from $0.2 \%$ to $1.3 \%$ in in the general population [2]. In China, the prevalence of hyperthyroidism is about $1.3 \%$ [3]. Graves' disease is a multisystem syndrome including hypermetabolic syndrome, diffuse goiter, eye signs, skin lesions, and thyroid acropathy. The basic treatments of Graves' disease are antithyroid drug treatment, radionuclide iodine treatment, surgical treatment and interventional embolization treatment. Family linkage analysis, candidate gene method and genome-wide association analysis (GWAS) have identified a greater number of Graves' disease susceptibility loci as well. In GWAS, the existing sequence variations are identified from the whole human genome and the variations that related to the disease are screen out. GWAS method has allowed many previously undiscovered genes and chromosomal regions to be detected which help provide many clues to the pathogenesis of complex diseases. However, all the variants that have been discovered have little to the heritability of GD. Therefore, different approaches were applied in this case study to identify the more susceptibility loci. 
In addition to twins study, the familial GD is the ideal object of study on contribution of genetic heritability to complex disease. Findings from family linkage analysis indicated that the $5 q 31-q 33,6 p, 7 q, 8 q, 10 q$, $12 q, 14 q$ and $20 q$ regions were related to GD susceptibility [4-6]. Subsequent research had verified that there was a linkage of familial GD to HLA gene and CTLA-4 gene. However, linkage analysis has not addressed the need for fine gene mapping in complex diseases and linkage analysis also requires a large familial sample size to localize the pathogenic genes by observing whether the genetic markers are cosegregated with the disease. In contrast, Whole Exome Sequencing can explore the susceptibility genes with a small sample size. Whole Exome Sequencing is an efficient strategy for fine mapping to determine the exact location of variant[7,8]. In the case study, WES was utilized to screen disease-causing genes from a three-generation familial GD patient with a strong genetic background of Chinese Han.

\section{Methods}

\section{Study participants}

A three-generation family from Zhanjiang, Guangdong Province had been targeted for the case study. There were 25 people in the family tree including 13 males and 12 females (Fig 1.). Five members were diagnosed with GD (Case 2 had type 2 diabetes simultaneously). Two healthy people in the first-degree relatives of the family were set as control group at the same time. Both the cases and control group were confirmed based upon medical history, physical examination, and results of thyroid function examination. All the five GD patients had typical clinical manifestation of hyperthyroidism such as heart and hands trembling. Four of the patients resorted to drug (Methimazole) for anti-thyroid treatment and one other patient resorted to $\mathrm{I}^{131}$ for anti-thyroid treatment. As of the month before the article was submitted, it was confirmed that the control group was still free of Graves' disease. Table 1 has the details of the participants.

\section{Thyroid function examination and Susceptibility Gene Screening}

Detection of thyroid hormones and TRAb by chemiluminescence method(Cobase411) was used and the reference range of indicators are: FT3: $2.3-6.8 \mathrm{pmol} / \mathrm{L} ; \mathrm{FT} 4: 10-23.5 \mathrm{pmol} / \mathrm{L} ; \mathrm{TSH}: 0.34 \sim 4.0 \mathrm{mIU} / \mathrm{L} ; \mathrm{TRAb}$ : $0 \sim 1.75 \mathrm{IU} / \mathrm{L}$. For preparation of DNA, genomic DNA from EDTA-treated peripheral blood was extracted according to DNA extraction kit manual (Tiangen Biochemical Technology Co., Ltd.)

The Agilent SureSelect Human All Exome Kit(Agilent) was used for exon capture. The sequencing processes were exon capture, hybrid library cleaning and purification, PCR amplification of exon DNA library, library quality detection, sequencing, and data analysis. The PCR reaction conditions of PCR Amplification was initially 30 seconds at $98^{\circ} \mathrm{C}, 10$ cycles of $98^{\circ} \mathrm{C}$ for 10 seconds, 10 cycles of $60^{\circ} \mathrm{C}$ for 30 seconds, 10 cycles of $72^{\circ} \mathrm{C}$ for 30 seconds, 10 cycles of $72^{\circ} \mathrm{C}$ for 5 minutes at $72^{\circ} \mathrm{C}$, followed by a final extension of $4^{\circ} \mathrm{C}$. The exome region was sequenced by illumine hiseq2500, and GATK standard procedure was adopted to calibrate the initial data. Quality control of raw reads was performed with fastqc. Transition and Transversion (SNV) and Insertion and Deletion (InDel) of each sample were detected 
though VarScan and GATK HaplotypeCaller. In addition, SNV stands for single nucleotide variants and SNP stands for single nucleotide polymorphism. Both concepts refer to single nucleotide changes, but SNPs are generally two-state and SNV has no such restriction. In addition, if the frequency of the singlebase variation in a species reaches a certain level, it is called SNP, and if the frequency is unknown (for example, only found in an individual), it is called SNV. Sanger sequencing was used to confirm the genotype variant of 6 genes (MAP7D2, SLC1A7, TRAF3IP3, PTPRB, PIK3R3, DISC1) that were in all the participants.

\section{Results}

\section{The quality of raw data}

The sequencing quality $Q$ value was used to evaluate the sequencing error rate of the base. The base quality value Q20 indicated that the error rate was 1\%. Similarly, the base quality value Q30 indicated that the error rate was $0.1 \%$. In the case study, the data revealed that the sequencing quality of the seven samples were high (table 2).

The base average coverage depth of all samples was larger than 100xwhich meant that the detected SNV was reliable.

\section{SNV/InDel detection and annotation of 7 samples}

The SNV/InDel locus that was discovered with both VarScan and GATK methods was to be of high quality. If they were not discovered by both VarScan and GATK methods, the locus was medium quality. There were 144169 high quality SNV/InDel locus involved in this study (table 3).

The variations carried by the patient were identified as susceptibility genes of GD in the three-generation family, including MAP7D2(c. 452C>T: p. A151V), SLC1A7(c. 1204C>T: p. R402C), TRAF3IP3(c. 209A>T: p. N70I), PTPRB(c. 3472A>G: p. S1158G), PIK3R3(c. 121C>T: p. P41S), DISC1(c. 1591G>C: p. G531R). All $\mathrm{SNV} / \mathrm{InDel}$ sites in the case study were rare variants according to several known population databases (Freq_Alt1000, Kaviar_20150923, ESP6500, gnomAD). In addition, Chinese Millionome Database (CMDB, https://db.cngb.org/cmdb/) were applied for the comparative analysis. CMDB contain considerable variation and their allele frequency information came from 141,431 unrelated healthy Chinese individuals (Phase I results). SNV function analysis indicated that all the SNV of MAP7D2, SLC1A7, TRAF3IP3, $P T P R B, P I K 3 R 3, D I S C 1$ were of nonsynonymous variations. The genotype of the 6 genetic variations from the 7 samples by Sanger sequencing was the same with the results from the whole exome sequencing(Figure 2). The PCR premiers of six genetic variants were shown in Table 5. Based on PolyPhen-2 prediction and the amino acids conservation analysis in orthologous species, the rs555004337 in TRAF3IP3, rs186466118 in PTPRB, and rs115181807 in PIK3R3 were likely to affect the protein function(Table 4 and figure 3 ). These genes involved in the Biological Process, Molecular Function, Cellular Component, and KEGG pathway were showed in an additional excel file. 


\section{Discussion}

GD is an autoimmune disease with complex etiology. With the extensive development of GWAS research, many GD susceptibility genes have been identified such as HLA, CTLA4, PTPN22, and TSHR[9]. Gene mutations may affect the antigen presentation, T cell signal transduction, B cell antibody production, thyroid hormone, and thyroid-related apoptosis which may lead to the occurrence of GD. The gene mutation effects provide a theoretical basis for GD's precise diagnosis and treatment. However, the current impact of GD susceptibility gene polymorphism on the expression of corresponding proteins is still unknown and research on the interaction between genes is limited in elucidating the role of gene polymorphism in disease pathogenesis.

In the case study, it presents a rare familial GD case in 5 patients in a three-generation family. The five patients are consistent with the general characteristic of GD patients which is that the GD is prone to attack women at the age of 30-60 [10]. All the members of the three-generation family came from the same district of Zhanjiang city and they have been living in similar environment which guarantees the consistency of environmental factors in this case study. Although the etiology of GD is complex and clear identification of potential factors for GD has not been completed, it is widely recognized that the genetic determinants such as HLA, CTLA-4, PTPN22, and CD40 have contributed to the risk of GD[11]. However, no variation of these former identified genes was found, but the following variations of MAP7D2, SLC1A7, TRAF3IP3, PTPRB, PIK3R3, DISC1, and SUPT2OHL were found in the familial GD. Furthermore, the variations in PTPRB, PIK3R3, and TRAF3IP3 were predicted to have alter the functions of the encoded protein. Familial GD of multigeneration is important for heritable studies because it avoids the genetic heterogeneity factor, so this case study may explain the genetic cause of the familial clustering of GD.

MAP7D2 (MAP7 domain containing 2) is located on X chromosome. MAP7D2 is specifically expressed in human brain tissue which has impact on the behavioral traits and cognition in human. MAP7D2 is also associated with sex-biased mental illnesses[12]. Previous studies has shown that gender predisposition to $\mathrm{GD}$ is associated with $\mathrm{X}$ chromosome inactivation $(\mathrm{XCl})$ migration[13]. Thus, the MAP7D2 study is likely to provide important general information about the reason why women are more vulnerable to GD. SLC1A7 and DISC1 are also susceptibility genes for mental illnesses. In one research, Keith A. Young et al. discovered that DISC1 gene played a vital role in post-traumatic stress disorder (PTSD) severity of US military veterans[14]. In another research, Fujita K, et al. revealed that SLC1A7 gene expression in peripheral blood leukocytes was responsible for the association between socioeconomic status and depressive mood in healthy adults[15]. We speculated that SLC1A7 and DISC1 are involved in regulating the symptoms of GD such as nervousness and irritability.

The protein encoded by PTPRB belongs to the family of protein tyrosine phosphatases (PTP). The activation of PTK (protein tyrosine kinase) was regulated through the binding of $\mathrm{SH} 2$ domains from PI3K(PIK3R3 gene encode). The balance of tyrosine protein phosphorylation was regulated by PTP/PTK which participated in cell signal transduction, cell growth regulation, differentiation, metabolism, transcription, immune responses, etc. Researches have demonstrated that the significant role of PTKs 
and PTPs were to modulate the tyrosine phosphorylation-dependent signaling pathways which were critical for the effector of NK cell and Neutrophil cell[16,17]. TRAF3IP3 is also highly expressed in CD34+CD38+CD7+ common lymphoid progenitors (CLPs) Furthermore, CD34+CD38+CD7+ cells have the capacity to differentiate into $B / N K / T$ cell which implies that TRAF3IP3 possibly may play a role in lymphoid development [18]. The overactivation of the T/B cell was regulated by $C T L A-4$ and $C D 4 O$ gene variants which has been confirmed in the pathogenesis of autoimmune diseases including GD. Therefore, further studies are necessary to figure out whether the variations of PTPRB, PIK3R3 and TRAF3IP3 are involved in the dysfunction of thyroid autoimmune.

The case study is about the susceptibility genes of a single three-generation family of Graves disease, but there are insufficient samples of similar families to verify the results of this study. Also, the frequency of susceptibility genes screened in this study has not been further verified in the population of patients with sporadic Graves disease and the relationship between these gene mutations and sporadic Graves disease is uncertain. Finally, the susceptibility genes screened this time need to be further studied at the protein molecular level to further determine the biological significance of these mutations.

\section{Conclusion}

To summarize, the WES was applied to establish an association between MAP7D2, SLC1A7, TRAF3IP3, $P T P R B, P I K 3 R 3, D I S C 1$ genes and the familial GD of a three-generation family. The findings in this cast studies are clues for further study and more verification and function researches are needed to explore these genes related to GD susceptibility.

\section{Abbreviations}

GD: Graves' disease; WE: Whole Exome Sequencing

\section{Declarations}

\section{- Ethics approval and consent to participate}

Informed written consent was obtained from all participants. In this study, no cases was under the age of 16. Ethical approval was provided by the the Ethics Committee of the Affiliated Hospital of Guangdong Medical University.

\section{- Consent for publication $\square$}

Written informed consent for publication of the case was obtained for each participant. In our study, one case was under 18 and the written informed consent for publication was obtained from his parents.

\section{- Availability of data and materials}


The datasets used and/or analyzed during the current study are available from the corresponding author upon reasonable request.

\section{- Competing interests}

The authors declare that they have no competing interests.

\section{- Funding}

Our research was financially supported by grants from China Postdoctoral Science Foundation Grant(Grant NO. 2019 M652859). The funding bodies only provided the financial means to buy reagents for experiments, and the funding bodies played no role in the design of the study and collection, analysis, and interpretation of data and in writing the manuscript.

\section{- Author contribution}

Designed the study: ZQH

Analyzed data: WL, MSL, HW

Collected data: YTC, ZHH

Manuscript editing: WL

Wrote the paper: ZQH, WGL

Supervision: WGL, AL

All authors read and approved the final manuscript.

\section{- Acknowledgements}

Not Applicable.

\section{Author details}

${ }^{1}$ Department of Endocrinology, The Second Affiliated Hospital of Guangzhou Medical University, Guangzhou, China

${ }^{2}$ Huizhou Health Sciences Polytechnic, Huizhou, China

${ }^{3}$ Department of Endocrinology, Affiliated Hospital of Guangdong Medical University, Zhanjiang, China

\section{References}


1. Brix, TH.; Kyvik, KO.; Christensen, K.; Hegedüs, L. Evidence for a major role of heredity in Graves' disease: a population-based study of two Danish twin cohorts. J Clin Endocrinol Metab. 2001; 86: 930-934.

2. Taylor, PN.; Albrecht, D.; ScholzGlobal, A.; Gutierrez-Buey, G.; Lazarus, JH.; Dayan, CM; Okosieme, OE. epidemiology of hyperthyroidism and hypothyroidism. Nat Rev Endocrinol. 2018;14: 301-316.

3. Lu, Z.; Zhong, N. Internal Medicine(M). Edition 7. Beijing; People's Publishing House. 2008; 712-721.

4. Sakai, K.; Shirasawa, S.; Ishikawa, N.; Ito, K.; Tamai, H.; Kuma, K.; Akamizu, T.; Tanimura, M.; Furugaki, K.; Yamamoto, K.; Sasazuki, T. Identification of susceptibility loci for autoimmunethyroid disease to 5q31-q33 and Hashimoto's thyroiditis to 8q23- q24 by multipoint affected sib-pair linkage analysis in Japanese. Hum Mol Genet. 2001; 10: 1379-1386.

5. Jin, Y.; Teng, W.; Ben, S.; Xiong, X.; Zhang, J.; Xu, S.; Shugart, YY.; Jin, L.; Chen, J.; Huang, W. Genomewide scan of Graves'disease: evidence for linkage on chromosome $5 q 31$ in Chinese Han pedigrees. J Clin Endocrinol Metab. 2003; 88: 1798-1803.

6. Tomer, Y.; Ban, Y.; Concepcion, E.; Barbesino, G.; Villanueva, R.; Greenberg, DA.; Davies, TF. Common and unique susceptibility loci in Graves and Hashimoto diseases: results of whole-genome screening in a data set of 102 multiplex families. Am J Hum Genet. 2003; 73: 736-747.

7. Glessner, JT.; Bick, AG.; Ito, K.; Homsy, J.; Rodriguez-Murillo, L.; Fromer, M.; Mazaika, E.; Vardarajan, B.; Italia, M.; Leipzig, J.; DePalma, SR.; Golhar, R.; Sanders, SJ.; Yamrom, B.; Ronemus, M.; lossifov, I.; Willsey, AJ.; State, MW.; Kaltman, JR.; White, PS.; Shen, Y.; Warburton, D.; Brueckner, M.; Seidman, C.; Goldmuntz, E.; Gelb, BD.; Lifton, R.; Seidman, J.; Hakonarson, H.; Chung, WK. Increased frequency of de novo copy number variants in congenital heart disease by integrative analysis of nucleotide variation array and exome sequence data. Circulation Research. 2014; 115: 884-896.

8. Brastians, PK.; Amaro, T W.; Manley, PE.; Jones, RT.; Dias-Santagata, D.; Thorner, AR.; Lawrence, MS.; Rodriguez, FJ.; Bernardo, LA.; Schubert, L.; Sunkavalli, A.; Shillingford, N.; Calicchio, ML; Lidov, HG.; Taha, H.; Martinez-Lage, M.; Santi, M.; Storm, PB.; Lee, JY.; Palmer, JN.; Adappa, ND.; Scott, RM.; Dunn, IF.; Laws, ER Jr.; Stewart, C.; Ligon, KL.; Hoang, MP.; Van, Hummelen P.; Hahn, WC.; Louis, DN.; Resnick, AC.; Kieran, MW.; Getz, G.; Santagata, S. Exome sequencing identifies BRAF variations in papillary craniopharyngiomas. Nature Genetics. 2014; 46: 161-65.

9. Simmonds MJ. GWAS in autoimmune thyroid disease: redefining our understanding of pathogenesis. Nat Rev Endocrinol. 2013; 9: 277-287.

10. Hemminki, K.; Li, X.; Sundquist, J.; undquist, K.; The epidemiology of Graves' disease: evidence of a genetic and an environmental contribution. J Autoimmun. 2010; 34: 307-313.

11. Tomer, Y. Mechanisms of autoimmune thyroid diseases: from genetics to epigenetics. Annu Rev Pathol. 2014; 9: 147-156.

12. Davies, W. Genomic imprinting on the $X$ chromosome: implications for brain and behavioral phenotypes. Ann N Y Acad Sci. 2010; 1204 Suppl: E14-9.

13. Simmonds, MJ.; Kavvoura, FK.; Brand, OJ.; Newby, PR.; Jackson, LE.; Hargreaves, CE.; Franklyn, JA.; Gough, SC. Skewed $\mathrm{X}$ chromosome inactivation and female preponderance in autoimmune thyroid 
disease: an association study and meta-analysis. J Clin Endocrinol Metab. 2014; 99: E127-131.

14. Young, KA.; Morissette, SB.; Jamroz, R.; Meyer, EC.; Stanford, MS.; Wan, L.; Kimbrel, NA. 5-HTTLPR and DISC1 risk genotypes for elevated PTSD symptoms in US military veterans. World Psychiatry. 2017; 16: 109-110.

15. Fujita, K.; Kuwano, Y.; Saijo, S. Negative perception of socioeconomic status with depressive mood down-regulates expression of PPBP and SLC1A7genes in peripheral blood leukocytes. Cogent Psychology. 2017; 4.

16. Vivier, E.; Nunès, JA.; Vély, F. Natural killer cell signaling pathways. Science. 2004; 306: 1517-1519.

17. Kruger, J.; Butler, JR.; Cherapanov, V.; Dong, Q.; Ginzberg, H.; Govindarajan, A.; Grinstein, S.; Siminovitch, KA.; Downey, GP. Deficiency of Src homology 2-containing phosphatase 1 results in abnormalities in murine neutrophil function: studies in motheaten mice. J Immunol. 2000; 165(10): 5847-5859.

18. Hoebeke, I.; De Smedt, M.; Stolz, F.; Pike-Overzet, K.; Staal, FJ.; Plum, J.; Leclercq, G. T-, B- and NKlymphoid, but not myeloid cells arise from human CD34(+)CD38(-)CD7(+) common lymphoid progenitors expressing lymphoid-specific genes. Leukemia. 2007; 21: 311-319.

\section{Tables}

Tab 1. The basic clinical characteristics of the object of study

\begin{tabular}{|c|c|c|c|c|c|c|c|}
\hline & Case 1 & Case 2 & Case 3 & Case 4 & Case 5 & Con 1 & Con 2 \\
\hline Year (2015) & death & 56 & 54 & 52 & 17 & 45 & 21 \\
\hline Sex & female & female & female & female & male & male & female \\
\hline Year of initial diagnosis & 1990 & 2006 & 2007 & 1992 & 2014 & - & - \\
\hline Smoking & - & - & - & - & - & - & - \\
\hline Drinking & - & - & - & - & - & - & - \\
\hline \multicolumn{8}{|l|}{ Clinical manifestation } \\
\hline Heart & + & + & + & + & + & - & - \\
\hline Proptosis & + & + & - & + & + & - & - \\
\hline Hands tremble & + & + & + & + & + & - & - \\
\hline Goiter & - & - & + & + & + & - & - \\
\hline Ophthalmopathy & - & - & - & + & - & - & - \\
\hline \multicolumn{8}{|l|}{ Serological test } \\
\hline FT3 (pmol/L) & 3.26 & 4.76 & 6.86 & 2.39 & 9.85 & 4.49 & 4.70 \\
\hline FT4 (pmol/L) & 16.57 & 17.60 & 21.61 & 7.71 & 26.50 & 16.45 & 15.94 \\
\hline TSH (mUL/L) & $\square 0.005$ & 0.118 & $\square 0.005$ & 62.10 & 0.072 & 1.18 & 0.740 \\
\hline TRAb (IU/L) & - & 2.38 & 4.13 & - & 5.75 & 1.27 & 1.04 \\
\hline Treatment & \multicolumn{4}{|c|}{ Thiamazole Thiamazole Thiamazole } & $\mathrm{I}^{131}$ & iamazole & - \\
\hline
\end{tabular}


+: positive; -: negative

Tab 2. Raw data sequencing data statistics

\begin{tabular}{|c|c|c|c|c|c|c|c|c|c|}
\hline & \multicolumn{4}{|l|}{ R1 } & \multicolumn{4}{|l|}{$\mathrm{R} 2$} & \multirow{3}{*}{$\begin{array}{l}\text { Mean Bait Coverage } \\
\text { (percentage) }\end{array}$} \\
\hline & Total & Reads & Q20 & Q30 & Total & Reads & Q20 & Q30 & \\
\hline & Reads & length & $(\%)$ & $(\%)$ & Reads & length & $(\%)$ & $(\%)$ & \\
\hline Case1 & 59415807 & $35-151$ & 99.98 & 97.51 & 59415807 & $35-151$ & 99.6 & 92.65 & 144.47 \\
\hline Case2 & 43894852 & $35-151$ & 99.98 & 97.60 & 43894852 & $35-151$ & 99.67 & 93.46 & 112.48 \\
\hline Case3 & 71415598 & $35-151$ & 99.97 & 97.61 & 71415598 & $35-151$ & 99.64 & 93.18 & 143.06 \\
\hline Case 4 & 74526096 & $35-151$ & 99.98 & 97.58 & 74526096 & $35-151$ & 99.64 & 93.41 & 200.99 \\
\hline Case 5 & 80885417 & $35-151$ & 99.98 & 97.57 & 80885417 & $35-151$ & 99.62 & 93.09 & 211.79 \\
\hline Con1 & 80289875 & $35-151$ & 99.98 & 97.55 & 80289875 & $35-151$ & 99.47 & 92.06 & 207.86 \\
\hline Con2 & 69913521 & $35-151$ & 99.98 & 97.50 & 69913521 & $35-151$ & 99.66 & 93.88 & 155.40 \\
\hline
\end{tabular}

"Q20 (\%)" and "Q30 (\%)" respectively indicate the ratio that the sequencing quality value Q in the raw data is not lower than Q20 and Q30.

Tab 3. The SNV/InDe locus number statistics in 7 samples

\begin{tabular}{lll}
\hline Category & SNV(N) & InDel(N) \\
\hline Both & 125581 & 18588 \\
Only Varscan & 51959 & 12118 \\
Only GATK & 5337 & 2250 \\
\hline
\end{tabular}

Table 4. The details of SNV/InDel information 


\begin{tabular}{|c|c|c|c|c|c|c|}
\hline Gene & $M A P 7 D 2$ & SLC1A7 & TRAF3IP3 & $P T P R B$ & PIK3R3 & DISC1 \\
\hline \multicolumn{7}{|l|}{ Information } \\
\hline Position & $X: 20074820$ & $1: 53556483$ & 1:209933593 & $12: 70956666$ & 1:46546408 & $1: 231906773$ \\
\hline exon & 4 & 8 & 3 & 14 & 2 & 6 \\
\hline SNP ID & rs750367268 & - & rs555004337 & rs186466118 & rs115181807 & rs56229136 \\
\hline Ref allele & G & G & A & $\mathrm{T}$ & G & G \\
\hline Alt allele & A & A & $\mathrm{T}$ & $\mathrm{C}$ & A & C \\
\hline Function & missense & missense & missense & missense & missense & missense \\
\hline $\begin{array}{l}\text { PolyPhen-2 } \\
\text { score }\end{array}$ & 0.139 (benign) & - & $\begin{array}{c}0.729 \text { (possibly } \\
\text { damaging) }\end{array}$ & $\begin{array}{c}0.521 \text { (possibly } \\
\text { damaging) }\end{array}$ & $\begin{array}{l}1 \text { (probably } \\
\text { damaging) }\end{array}$ & 0.059 (benign) \\
\hline $\begin{array}{c}\text { Freq_Alt } \\
(1000)\end{array}$ & - & 0.000199 & 0.001797 & 0.004193 & - & 0.000599 \\
\hline Kaviar_ & 0.0000194 & 0.0000388 & 0.0006015 & 0.0015006 & - & 0.0003428 \\
\hline \multicolumn{7}{|l|}{20150923} \\
\hline ESP6500 & - & - & - & - & - & 0.000077 \\
\hline gnomAD & 0.000011 & 0.000028 & 0.0006 & 0.0019 & 0.000022 & 0.0004 \\
\hline CMDB & - & - & - & 0.0038 & 0.0051 & - \\
\hline \multicolumn{7}{|l|}{ Genotype } \\
\hline Case 1 & $\mathrm{G} / \mathrm{A}$ & $\mathrm{G} / \mathrm{A}$ & $\mathrm{A} / \mathrm{T}$ & $\mathrm{T} / \mathrm{C}$ & $\mathrm{G} / \mathrm{A}$ & $\mathrm{G} / \mathrm{C}$ \\
\hline Case 2 & $\mathrm{G} / \mathrm{A}$ & $\mathrm{G} / \mathrm{A}$ & $\mathrm{A} / \mathrm{T}$ & $\mathrm{T} / \mathrm{C}$ & $\mathrm{G} / \mathrm{A}$ & $\mathrm{G} / \mathrm{C}$ \\
\hline Case 3 & $\mathrm{G} / \mathrm{A}$ & $\mathrm{G} / \mathrm{A}$ & $\mathrm{A} / \mathrm{T}$ & $\mathrm{T} / \mathrm{C}$ & $\mathrm{G} / \mathrm{A}$ & $\mathrm{G} / \mathrm{C}$ \\
\hline Case 4 & $\mathrm{G} / \mathrm{A}$ & $\mathrm{G} / \mathrm{A}$ & $\mathrm{A} / \mathrm{T}$ & $\mathrm{T} / \mathrm{C}$ & $\mathrm{G} / \mathrm{A}$ & $\mathrm{G} / \mathrm{C}$ \\
\hline Case 5 & $\mathrm{~A} / \mathrm{A}$ & $\mathrm{G} / \mathrm{A}$ & $\mathrm{A} / \mathrm{T}$ & $\mathrm{T} / \mathrm{C}$ & $\mathrm{G} / \mathrm{A}$ & $\mathrm{G} / \mathrm{C}$ \\
\hline Con 1 & $\mathrm{G} / \mathrm{G}$ & $\mathrm{G} / \mathrm{G}$ & $\mathrm{A} / \mathrm{A}$ & $\mathrm{T} / \mathrm{T}$ & $\mathrm{G} / \mathrm{G}$ & $\mathrm{G} / \mathrm{G}$ \\
\hline Con 2 & $\mathrm{G} / \mathrm{G}$ & $\mathrm{G} / \mathrm{G}$ & $\mathrm{A} / \mathrm{A}$ & $\mathrm{T} / \mathrm{T}$ & $\mathrm{G} / \mathrm{G}$ & $\mathrm{G} / \mathrm{G}$ \\
\hline
\end{tabular}

CMDB: Chinese Millionome Database; -: No found.

Table 5. The PCR primers of six genetic variants 


\begin{aligned} & \hline Gene: variant \multicolumn{1}{c}{ premiers } \\ & \hline MAP7D2: c. 452C>T F-ATCTGAAAGTGGTGCCTCTGAA R-TAGCCTAGCCGCATTGTTTACT \\ & SLC1A7: c. 1204C>T F-GTTGACCTGGGCGATGAAGA \\ & R-AAACACCTCCCTCATAGGAAGAAC \\ & TRAF3IP3: c. 209A $>$ T F-AACAGGTGCTTGGAGGTCATC \\ & R-AGCACACAGCAGTATGTCCCTT \\ & PTPRB: c. 3472A>G F-GGAAACTAAGGACCAACCAAGG \\ & R-CACTGCATTTCCCTCCCTCA \\ & PIK3R3: c. 121C>T F-GCATTCTAGTTACCTTGAAATATCC \\ & R-CATACCTTGGTTAGTGAGCTGCT \\ & DISC1: c. 1591G>C F-GGAAATAGAGGAGCAAGAGCAG \\ & R-CAGACTGCTTGGGAAATGTTAG \\ & \hline\end{aligned}

\section{Figures}

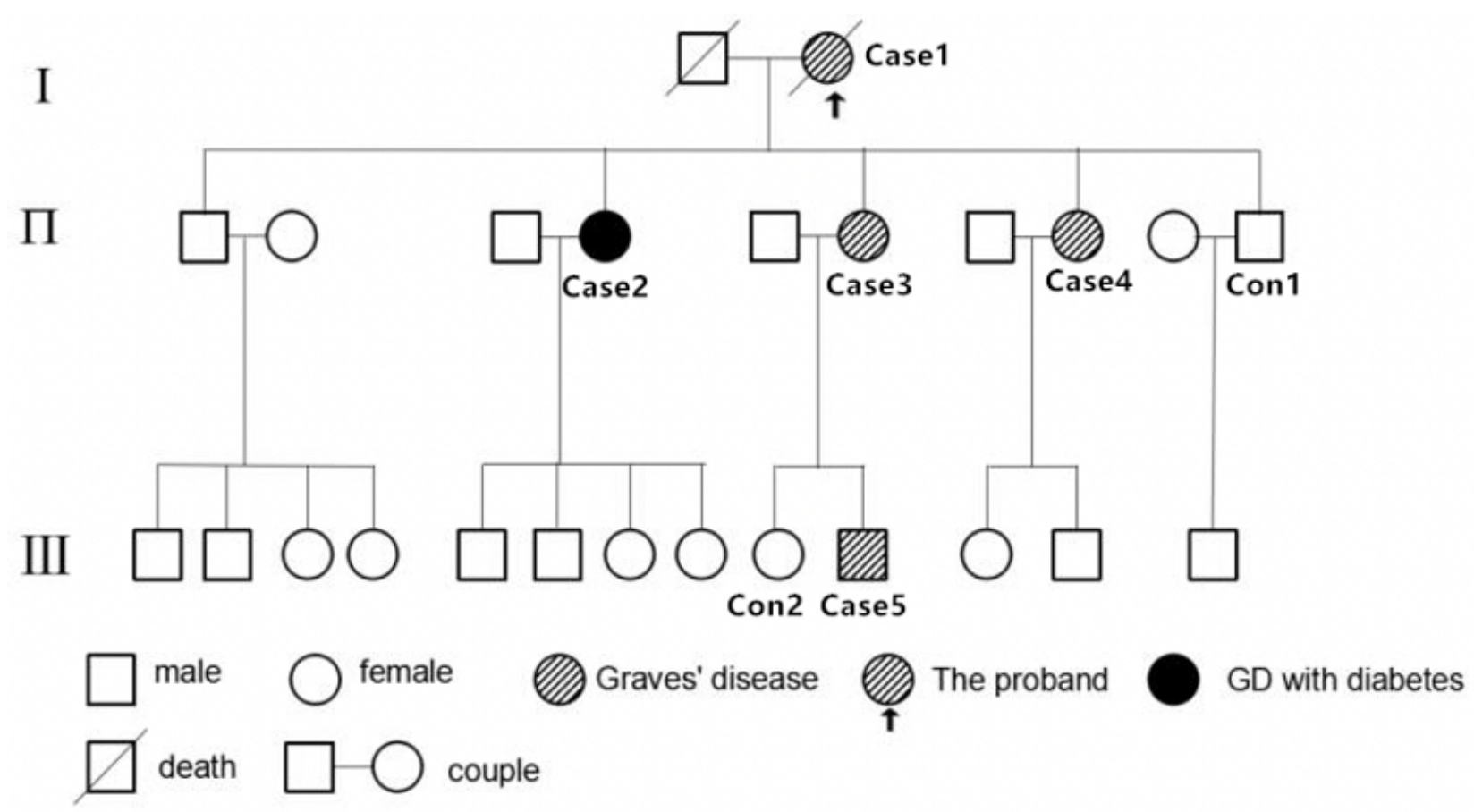

Figure 1

Pedigree of study family 


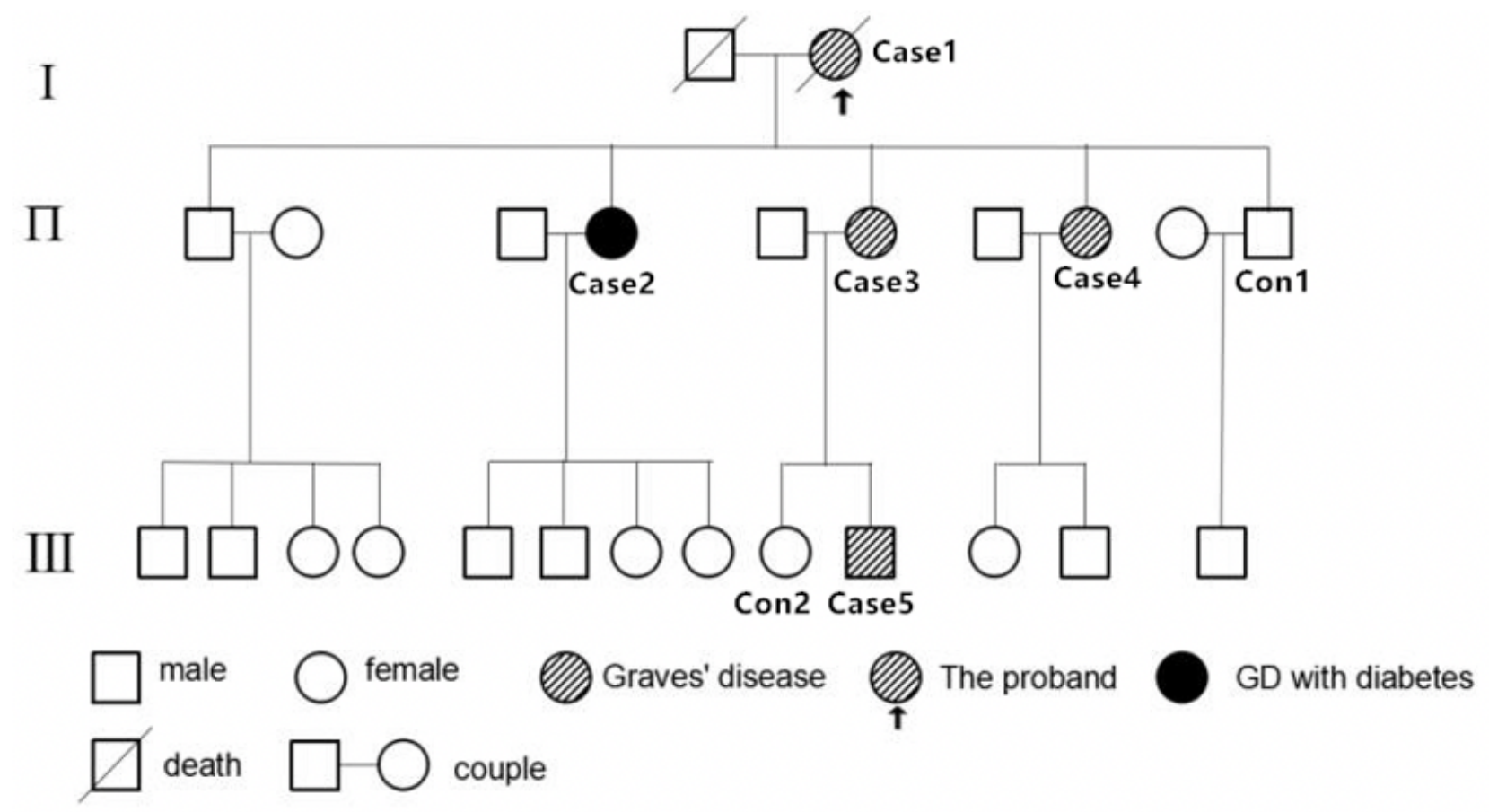

Figure 1

Pedigree of study family

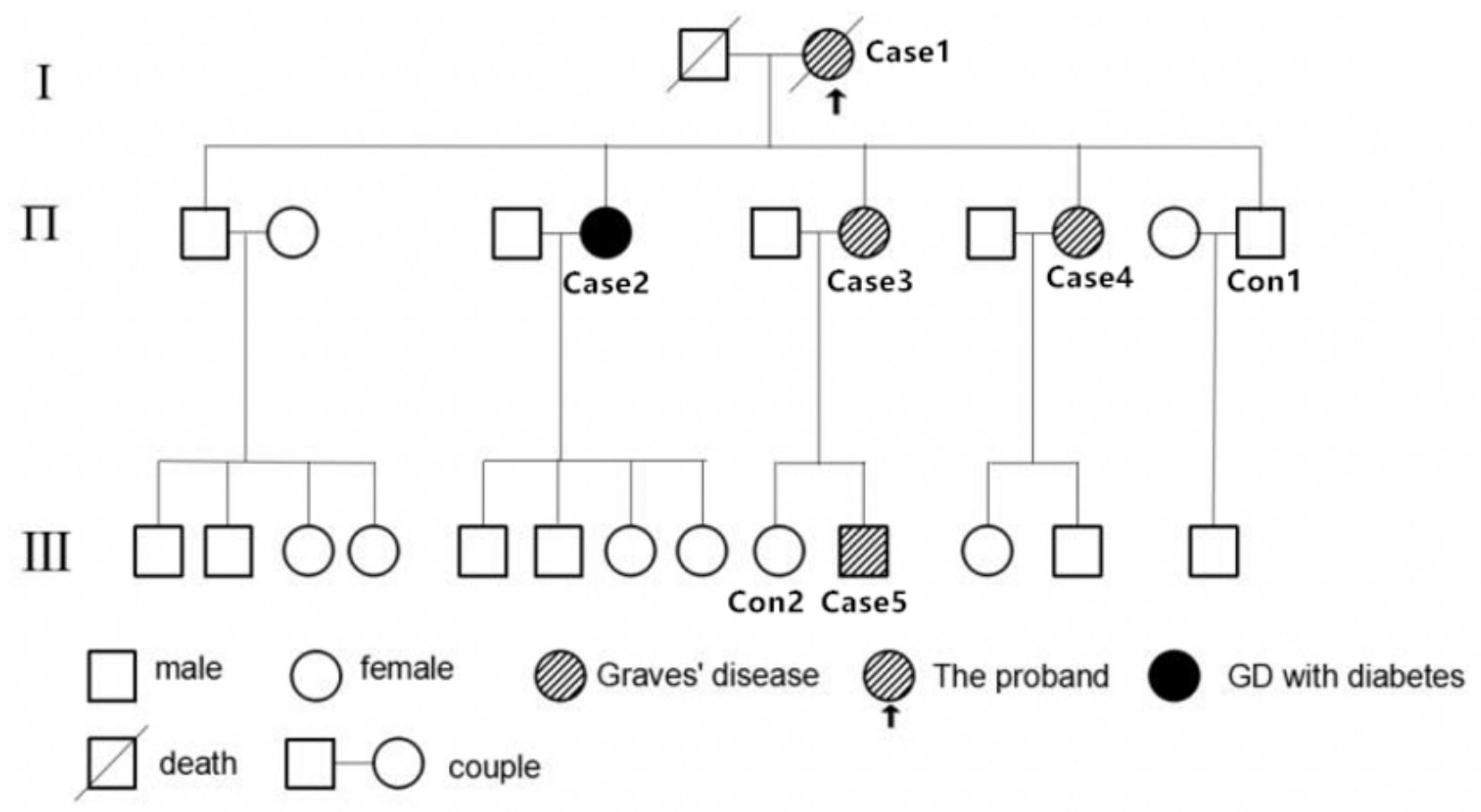

Figure 1 
Pedigree of study family

\begin{tabular}{|c|c|c|c|c|c|c|}
\hline & 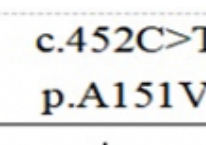 & 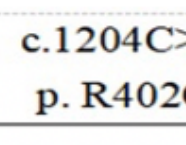 & 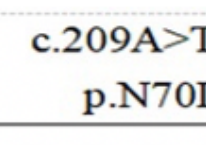 & 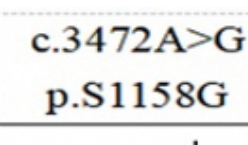 & 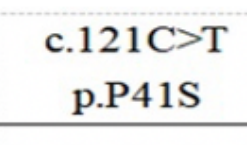 & 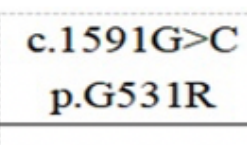 \\
\hline & $\Lambda$ & & & & 1 & \\
\hline & & & & & & \\
\hline & & & & & & \\
\hline & & & & & & \\
\hline & & & & & $M$ & \\
\hline & & Wh & W & & M & \\
\hline & & & & & & \\
\hline
\end{tabular}

Figure 2

The Sanger sequencing of variations for the 7 participants 


\begin{tabular}{|c|c|c|c|c|}
\hline & 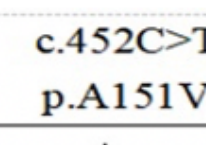 & 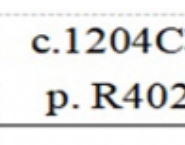 & & 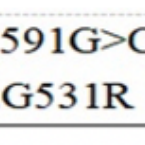 \\
\hline & & & & \\
\hline & & & & \\
\hline 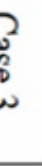 & iv & & & \\
\hline & & & & \\
\hline & & & & \\
\hline & & WV & & \\
\hline & & & & \\
\hline
\end{tabular}

Figure 2

The Sanger sequencing of variations for the 7 participants 


\begin{tabular}{|c|c|c|c|}
\hline & 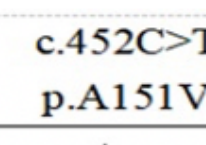 & 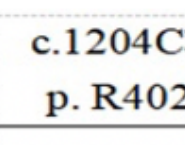 & 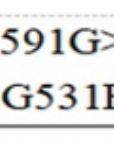 \\
\hline & & & \\
\hline $\begin{array}{l}3^{2} \\
x_{2}\end{array}$ & TIV & & \\
\hline 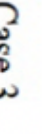 & $\pi$ & & \\
\hline & & & \\
\hline & & & \\
\hline & & iv & \\
\hline & & & \\
\hline
\end{tabular}

Figure 2

The Sanger sequencing of variations for the 7 participants 


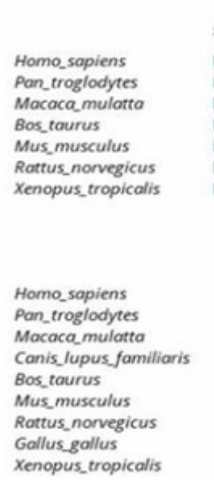

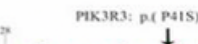

FY IEMDPPALPPKPPKPMTSAVPNG FYIEMDPPALPPKPPKPMT SAVPNG FYIEMDPPALPPKPPKPMTSAVTNG FY EMDPPALPPKPPKPMT FY IEMPPPALPPKPPKPVTSAVTNG FYI EMDPPVLPPKPPKSMTSLSTDG

PTPRB: P(SIISSG)
$\downarrow$
RMYKMVI VTHSGELSNES
RMYKMV I VTHSGELSNES
RMYKMV I VTHSGELSNES
RMYKMV I VTHSGELSNES
RMYRMV I VTHSGELSNES
RMYKMV I VTHSGELSNES
RMYKMV I VTHSGELSNES
RMYRMV I VTHSGDLTNES
RLYKMV I VTHSGSLTNES

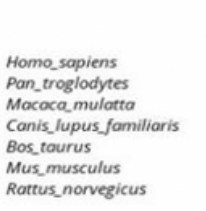

a TRAF3P3: $P(N 701)$ QQFFRRR $\frac{1}{\text { LLELEEKG }}$ QQFFRRRNLELEEKG QQFFRRRNLELEEKG REFFRR QQFFRRRNLEVEEKG LQFLKRRNLEEEKKG

SLC1A7: P. R R02C)

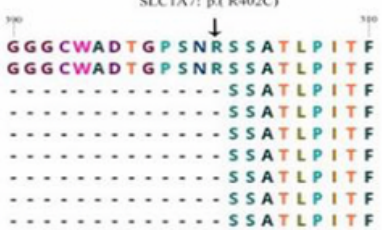

Home_sopiens Pan_troglodytes Mococamulatto Canis_lupus_familicitis Mus_musculus

Homo sapiens Pan_troglodytes Macaca mulatta Canis_lupus_familiaris Mus_musculus Rattus_norvegicus Gallus_gallus Xenopus_tropicalis
9. DISCI: PrGS31R KALQDTLASAGQIPFHAEP KALQDTLASAGQIPFHAEP KALLDTLASAGOIPFHAE KALHDTLAFANQIPICAEP KALGETLTSANQAPFQVEP KALGETLTSARWAPERVEP

$$
\text { MAP7D2: p.(A15IV) }
$$

K- KKYSWGAPLAIGPGGHD K- KKYSWGAPLAIGPGGHD K - KKY SWG APLAIGPGGHD K- KKCSWGASLATGPGGRD K- KKCSWAG S.- PGPGGRD K- KKC SWAG SAAS GPGGRD KQKRWSWG GALAAGSGGRD KQKRWSWGGALVAGA-GRD

\section{Figure 3}

Amino acids conservation in orthologous species for the variants.

Homo_sopiens
Pan_troglodytes
Mocaca_mulatta
Bos_tourus
Mus_musculus
Rattus_norvegicus
Xenopus_tropicalis


Homo_sapiens
Pan_troglodytes
Macaca_mulotta
Canis_lupus_familiaris
Bos_taurus
Mus_musculus
Rattus_norvegicus
Gallus_gollus
Xenopus_tropicalis

$$
\text { PIK3R3: PC(PAIS) }
$$

$$
\text { FYI EMDPPALPPK }
$$

FY IEMDPPALPPKPPKPMTSAVPNG FYIEMDPPALPPKPPKPMTSAVPNG FYI EMDPPALPPKPPKPMTSAVTNG FYIEMDPPALPPKPPKPMTSAITNG FYIEMDPPALPPKPPKPMTPAVTNG FYI EMDPPALPPKPPKPVTSAVTNG
FYIEMDPPVLPPKPPKSMTSLSTDG

PTPRB: P(SIISSG)
$\downarrow$
RMYKMVI VTHSGELSNES
RMYKMV I VTHSGELSNES
RMYKMVI VTHSGELSNES
RMYKMV I VTHSGELSNES
RMYRMV I VTHSGELSNES
RMYKMVIVTHSGELSNES
RMYKMV IVTHSGELSNES
RMYRMV IVTHSGDLTNES

Homo_sapiens
Pan_troglodytes
Canis_lupus_familiaris
Bos_taurus
Mus_musculus
Rattus_norvegicus
Gallus_gallus
Danio_rerio
Xenopus_tropicalis

Home_sapiens Pan_troglodytes Macaca mulatta Canis_lupus_familiaris Bos_tourus Mus_musculus Rattus_norvegicus

$$
\text { 1. TRAF3P3: } p \text { ( N701) }
$$

QQFFRRR N LELEEKG QQFFRRRNLELEEK QQFFRRRNLELEEKG REFFRRRDLEVEETG QQFFRRRNLEVEEKG LQFLIKRRNLEEEKKG LQFLRRRNLEEEKG

StC1A7: P. R R02C)

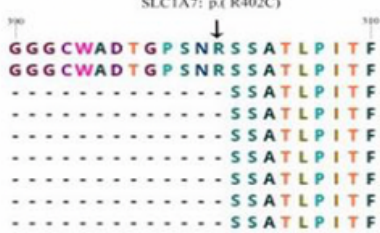

Home_sapiens Pan_troglodytes Mococa.mulotto Canis_lupus_familiaris Mus_musculus Rattus_norvegicus

Homo_sapiens

Homo_sapiens
Pan_troglodytes Pan_troglodytes Canis_lupus_familiaris Mus_musculus Rattus,norvegicus Gallus, norvegicus Gallus_gallus
Xenopus,tropicalis

$$
\text { 29. DISCI: } p(65318)
$$
KALQDTLASAGQIPFHAEP KALQDTLASAGQIPFHAEP KALQDTLASAGQI PFHAEP KALHDTLAFANQI PICAEP KALGETLTSANQAPFQVEP KALGETLTSARWAPFRVEP

$$
\text { 14. MAP7D2: P(AISIV) }
$$

K- KKYSWGAPLAIGPGGHD K- KKYSWGAPLAIGPGGHD K- KKYSWGAPLA I GPGGHD K- KKCSWGAS LATGPGGRD K- KKCSWAGS.-PGPGGRD $K$ - KKCSWAGSAASGPGGRD KOKRWSWGGALAAGSGGR RQKRWSWGALAAGSGGRD

\section{Figure 3}

Amino acids conservation in orthologous species for the variants.

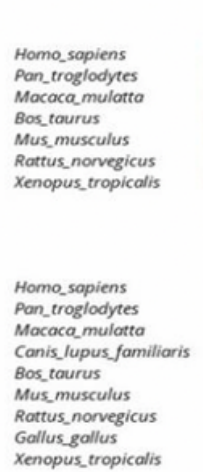

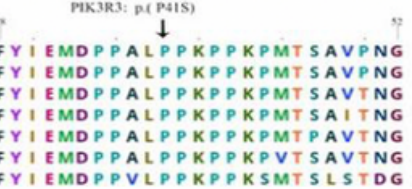

Pes PTPRB: P(SIIS8G)
$\downarrow$

RMYKMVI VTHSGELSNES RMYKMVIVTHSGELSNES RMYKMVIVTHSGELSNES RMYKMVIVTHSGELSNES RMYRMVIVTHSGELSNES RMYKMVIVTHSGELSNES RMYKMVIVTHSGELSNES RMYRMVIVTHSGDLTNES

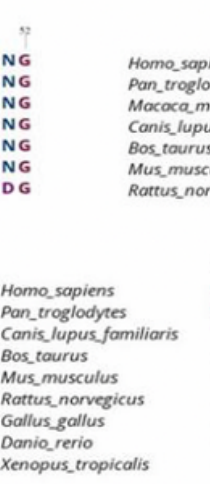

Homo_sapiens an_troglodytes Macoca mulatta tourus

Mus_musculus

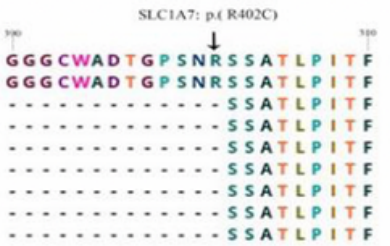

a TRAF3IP3: $P$ ( N N 701$)$ QQFFRRRNLLLEEKG QQFFRRRNLELEEKG QQFFRRRNLELEEKG
QQFFRRRLELEEKG
REFFRRRDLEVEETG REFFRRRDLEVEETG QQFFRRRNLEVEEKG LQFLKRRNLEE EKKG Canis_lupus familienis Danio_rerio Xenopus_tropicalis

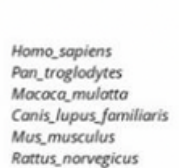

(7) DISCI: pigs31R

KALQDTLASAGQIPFHAEP KALLDTLASAGQIPFHAEP KALQDTLASAGQI PFHAEP KALHDTLAFANQIPI CAEP KALGETLTSANQAP FQVEP
KALGETLTSARWAPFRVEP

Rottus_norvegicus

Homo_sapiens Pan_troglodytes Macaca mulatto Canis_lupus_familiaris Mus_musculus Rattus_norvegicus Gallus_gallus Xenopus_tropicalis

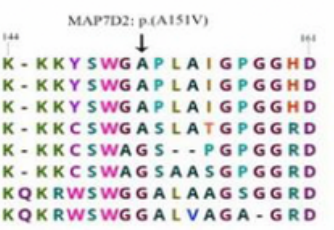

Figure 3 
Amino acids conservation in orthologous species for the variants. 